\title{
Dental Disease Burden Snacking, and Tooth Brushing Habits and Among 13-17-Year-Olds with Fluorosis Compared to those without Dental Fluorosis in Kajiado Kenya
}

\author{
Gladys N Opinya ${ }^{1 *}$ and Mavindu Mildred Ndoti ${ }^{2}$ \\ ${ }^{1}$ Professor of Paediatric Dentistry, Department of Paediatric Dentistry \& Orthodontics, School of Dental Sciences, College of Health Sciences, \\ University of Nairobi, Kenya
}

${ }^{2}$ Department of Paediatric Dentistry \& Orthodontics, School of Dental Sciences, College of Health Sciences, University of Nairobi, Kenya

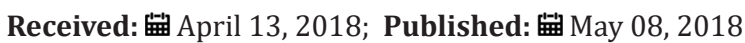

*Corresponding author: Gladys Opinya, Department of Paediatric Dentistry \& Orthodontics, School of Dental Sciences, College of Health Sciences, University of Nairobi

\section{Abstract}

The dental disease burden of periodontitis, gingivitis caries, and fluorosis has to be assessed objectively with patients understanding and therefore rationalise planning for oral health resources, utilization, and personnel distribution to tackle the disease burden. The study sought to assess the prevalence of dental fluorosis and the snacking and brushing habits to determine the dental disease burden, among 13-17- year- olds who were affected by dental fluorosis in comparison with those who were not affected with dental fluorosis in Kajiado North District of Kenya. The study cross-section and it compared dental disease burden among two age-matched population groups one with varying degrees of dental fluorosis and the second group without dental fluorosis teeth in primary school children aged between 13-15 years of age. Nine primary schools were randomly selected in Kajiado North County which had been purposively selected. The instruments of examination were a questionnaire on child's biodata. Disease burden was determined through a clinical examination for each child under natural light. Plaque and gingival scores, dental caries the decayed, missing, filled teeth (DMFT) were, and dental fluorosis was assessed using the Thylstrup Fejerskov index (TFI).

The study involved 248 children, who were matched for age and gender aged between $13-17$ years with a mean age of $14.75 \pm 1.45$ years. A total of 3472 teeth were examined, and prevalence of dental fluorosis in 3472 teeth of 124 children who were matched for age and gender with 124 without dental fluorosis was 3,375 (97.2\%) of the teeth surfaces. The prevalence dental fluorosis in 1680 maxillary teeth was (96.9\%) while mandibular teeth surface it affected 1690 (97.5\%) teeth. The differences were significant with a Chi-square test $=85.67$ d.f $=12, p=0.001$ at $95 \%$ CL. The mean plaque score of $0.98 \pm 0.61$ in children with dental fluorosis was lower compared with the mean plaque of $1.24 \pm 0.69$ for children without fluorosis. The difference significant with a Pearson Chi square $=72.540$ d.f $=12 \mathrm{p}=0.002$ at $95 \% \mathrm{CL}$. The children with fluorosis who brushed once after breakfast had the lowest plaque scores of $0.85 \pm 0.5$ compared to those without dental fluorosis and the difference were statistically significant [one-way ANOVA F=2.97, $\mathrm{p}=0.003$ at $95 \%$ CL. The gingival index for that ith fluorosis was $0.46 \pm 0.55$ and individuals without fluorosis the gingival index was $0.48 \pm 0.53$, and the difference was insignificant. However, the prevalence of gingivitis in girls was $139(93 \%)$ while the boys had a prevalence of 77(79\%). The difference was statistically significant difference, Pearson Chi-square test=75.34, d.f $=12, \mathrm{p}=0.001$ at 95\% CL. Periodontitis was found in 3(1.2\%) participants of those with dental fluorosis none of those with dental fluorosis were affected by periodontitis.

The caries experience for the 248 children was at a low mean DMFT of $0.45 \pm 1.15$. The individuals with dental fluorosis had a mean DMFT of $0.54 \pm 1.24$ while those without dental fluorosis had a mean DMFT was $0.36 \pm 1.04$, and the difference in the mean DMFT with a t-test was insignificant. In general children with dental fluorosis, who consumed sugary snacks had higher mean 
DMFTs when compared with children without dental fluorosis who consumed sugary snacks. Although there was a higher disease burden in individuals with dental fluorosis when compared with those without dental fluorosis, the difference was insignificant with a paired $t$-test, where $t=1.291$, d.f $=3, p=0.287$ at $95 \%$ CL. In conclusion, the individuals who had varying severities of dental fluorosis with frequent snacking had higher DMFT. Also the disease burden was higher in children with dental fluorosis.

Keywords: Fluorosed Teeth; Disease Burden; Snacking; Adolescents

Abbreviations: DMFT: Decayed Missing, Filled Teeth; TFI: Thylstrup Fejerskov index; WHO: World Health Organization; TFI: Thylstrup and Fejerskov index

\section{Introduction}

The World Health Organization (WHO) statistics indicate that dental caries and periodontitis constitute the most critical globaloral health disease burden [1]. However, the distribution and severity of oral diseases vary in different parts of the world and within the same country or region [2]. In the Kenyan situation, The 13-17 year olds affected by fluorosis may have a combination of other oral diseases like caries and periodontitis, and likewise, those not affected by dental fluorosis may suffer from similar problems. The treatment needs of these two populations are often varied depending on the severity of their conditions and assessments. Bacteria involved in dental caries dimineralise he hard tooth structure including enamel, dentine, and cementum which progressively break down through demineralization Rosenberg [2]. Many factors are associated with dental caries where the diet, host and the microbial flora interact over a period in such a way as to encourage demineralization of the tooth enamel with resultant caries formation. Dental caries affects many children making it a public health concern and is likely to increase in cases of severe dental fluorosis due to enamel pitting that encourages plaque retention. Affected teeth by fluorosis are usually sensitive discouraging plaque control measures through tooth brushing. Dental caries is counted among the common diseases in the world today. Evidence from WHO indicates that dental caries is less prevalent in the developed compared to the developing countries. The World Health Organization considers dental as a significant problem in oral health in the industrialized countries, affecting $60-90 \%$ of schoolchildren [3]. The incidence of dental caries is expected to increase in many developing countries in Africa, due to an increase in sugar intake [3]. A national oral health survey 2015 reported a DMFT of 0.42 in adolescents aged 11=7 years while Ng'anga an. among 13-15-year-olds in Kenya had shown a mean DMFT of $1.8[4,5]$. Ng'ang'a showed that the under 18 - year - olds had DMFT 0.2-1.8; the 12-15-year - olds had a DMFT of 1.2-1.9 [6]. A study by Owino showed an overall prevalence of dental caries among 12 -year-olds was $50.3 \%$ while its prevalence when only the permanent teeth were considered was $44.5 \%$ with a mean DMFT of $0.92 \pm 50$ [7].

Epidemiological studies have reported differing findings on the association between dental fluorosis and dental caries experience. The mixed epidemiological results were published in a South Africa study by Ockerse which indicated severe fluorosis to have been a predisposing cause of dental caries [8]. Whereas studies by
Chibole in Kenya, Cunha - Cruz. in the USA and Tagliaferro indicated a direct relationship between the severity of dental fluorosis and dental caries [9-14]. A study on dental fluorosis, caries experience and snack intake of in 275 adolescents 13-15 year olds in Kenya 88(52\%) had TFI (Thylstrup and Fejerskov index) score 1-4 severity of dental fluorosis and a corresponding mean DMFT of 1.5361 .005 . Furthermore, 82 (48.2\%) of the 13-17 year olds had severe degrees of dental fluorosis of TFI scores 5-9 and a related DMFT of $1.85 \pm 24[13,14]$. Wondwossen also, correlated enamel fluorosis and dental caries in U.S schoolchildren and reported permanent maxillary right first molars which had dental fluorosis consistently had lower levels of caries experience than did healthy molars [15]. Another study by Iida. showed that teeth with fluorosis were more resistant to caries [16]. A survey conducted in Namibia by Berndt et al. indicated that high concentrations of fluoride in drinking water alone do not result in acceptable caries levels so that there are other factors involved in the causation of dental caries [17]. Dental fluorosis is more likely to occur in children exposed to levels of fluoride above the recommended $1 \mathrm{ppm}$ between 20 and 30 months of age. It was further noted by Rodrigues et al. that the critical period for the risk of dental fluorosis development is between one and four years of age and that there is no risk after eight years of age [18]. The clinical appearance has been classified using several indices and the three principal ones in use today include the Dean's. The Thylstrup and Fejerskov and Horowitz indices although a recent Fluorosis Risk Index, was developed by Pendrys [13,19-22]. The Thylstrup and Fejerskov Index (TFI) was found to be appealing to clinicians and epidemiologists by Rozier since it corresponds closely to histopathological changes that occur to enamel due to dental fluorosis, thereby having biological validity [23]. A study conducted in Tanzania by Roman showed that based on this index varying degrees of fluorosis are scored with mild fluorosis being TF 1-3, moderate TF 4-5, and severe TF 6-9 [24]. The prevalence of dental fluorosis in permanent teeth in areas with fluoridated water had increased from $10-15 \%$ in the 1940 s to as high as $70 \%$ in the USA by Marshal et al. [25]. The Centers for Disease Control/ National Centre for Health Statistics in the USA reported an increase in the prevalence of dental fluorosis of $41 \%$ among 12-15-year-olds Beltran-Aguilar [26].

\section{Materials and Methods}

The demographic and geographic characteristics of Kajiado North District is $21,902.9$ Kilometres in size, and it has seven 
administrative divisions of Ewaso, Ngong, Magadi, Mashuru, Central, Namanga, and Isinya with a population of 466,130 consisting of (228, 118 females and 238,012 males. Kajiado stands at an altitude of 500 Metre in the lake Magadi region to about 2,500 meters in Ngong hills area. The average annual rainfall of $500 \mathrm{~mm}$ around Lake Amboseli \& Magadi to $1250 \mathrm{~mm}$ around Kilimanjaro slopes with a rainfall pattern of bimodal, short rain: - October-NovemberDecember while the long rains occurred between March to May. The temperatures are a mean maximum of $34^{\circ} \mathrm{C}$ around Lake Magadi to a mean minimum of $10^{\circ} \mathrm{C}$ on the foothills of Mount Kilimanjaro and Ngong Hills. The average annual potential evaporation ranges from 1600 to $2200 \mathrm{~mm}$ which means that for a considerable part of the year there is a moisture deficit. The vegetation is open grassland, wooded grassland, bushed grassland, wood, and bushland.

The study population comprised of 13-17-year-olds by date of birth who was born and brought up in Kajiado North District in the first seven years of life. The target population involved 34,122 children aged 13-17 years according to the Kenyan population and housing census 2009 for Kajiado North District. The public primary and secondary school enrolment was approximately 19,065 for ages 13-17 years in the year 2011 in Kajiado North District. Those aged 13-17 years in the selected schools were 3,473 and were $10 \%$ of the target population according to the District Education Office in Kajiado District, and only the ones who met the inclusion criteria were recruited into the study. The formula for comparing two groups was applied to calculate the sample size. A study done to determine dental fluorosis, caries experience and snack intake among children in Kenya found that 61.8\% 13-17-year-olds had severe degrees of dental fluorosis of TFI scores 5-9 and $38.2 \%$ had a TFI score of zero [14].

The formula for sample size determination in comparison of two groups was applied using the prevalence of caries of $61.8 \%$ for fluorosis and $38.2 \%$ for the group without fluorosis as shown; $\mathrm{N}=$ $2(\mathrm{Z} 1-\alpha / 2+\mathrm{Z} 1-\beta) 2 \mathrm{p}(1-\mathrm{p}) /(\mathrm{p} 1-\mathrm{p} 2) 2$. Where $\mathrm{N}=$ desired sample size and $2=$ Confidence level at $95 \%$ (standard value of 1.96); Z1- $\beta$ $=1.28$ for $\beta=10 \%$ (i.e. $90 \%$ power); $\mathrm{p}=$ Mean difference between prevalence of p1 (61.8\%) and p2 (38.2\%); $d=$ Level of precision at $5 \%$ (standard value of 0.05$) . \mathrm{N}=2 \times(1.96+1.28) 2 \times(0.50) \times$ $(1-0.50)=94.24 /(0.618-0.382) 2 ; \mathrm{N}=94$ per group, a minimum total of 188 although 248 were recruited increase the power of the study. Purposive sampling was done for Kajiado North district because it is a high fluoride area located in the Rift Valley Province in Kenya. Out of five education zones in the district, Ongata Rongai and Ngong Divisions were selected conveniently as an earlier study had reported high fluoride in water [14]. The two zones had twenty public schools out of which four secondary schools and five primary schools were selected through simple random technique as well as the 248 study participants comprising of 98 males and 150 females matched for age and gender and divided into two equal groups (with and without fluorosis). A random sampling of boreholes in the region was done to identify ten boreholes and a spring whose water was drawn and tested for fluoride levels.

Data collection was done partly using a self-administered semi-structured questionnaire was used to collect data on sociodemographic information, oral hygiene, dietary practices and health seeking behaviour. Also, a clinical examination for plaque, gingival scores, dental caries, gingivitis, periodontitis. The TFI scores were recorded in clinical examination forms using WHO assessment form 2004 for caries, Loe and Silness for gingivitis, Silness and Loe for plaque scores and CPITN for periodontitis [13,27-29]. Clinical examination was done under a shade using natural light with the patient lying on a coach. A dental mirror, probes, periodontal probe, sterile gauze and disposable gloves were used. The teeth were cleaned of plaque and food debris using sterile cotton gauze for TFI scores after scoring plaque scores. Water samples were collected using clear sterile plastic bottles which were rinsed three times with water from the source before drawing the samples. The containers were labeled, tightly cocked and transferred to the Ministry of Public Health, Government Chemist laboratories for fluoride testing. These represented a majority of the communities' source of water for the children who participated in the study. The location and depths the boreholes were obtained from the Ministry of Water, Kajiado North. Fluoride testing in the laboratory was by the column colorimetric assay method. Before data collection, pretesting of the study questionnaire was done to ascertain the validity of the data collected in the field.

The calibration in the field was for TFI scores in the randomly selected schools whose children did not participate in the primary study. A Cohen Kappa agreement of $0.8(n=22)$ for interexaminer reliability showing acceptable agreement between the examiners. During data collection, every tenth child was re-examined, and the intra-examiner Cohen Kappa agreement for TFI was $0.93(n=24)$. All the clinical measurements were done by the PI and data entered by trained data clerks. The quality of data was ensured during the entire study process primarily at the data collection point to include completeness of questionnaires and validity of responses. Quality control through data cleaning and validation was ensured by counter-checking frequencies in the computer. The findings from the study were organized in the form of frequency tables, pie charts, and figures.

Computations to calculate disease burden (caries experience, the prevalence of gingivitis and periodontitis), treatment needs and the cost of treatment were done. The independent variable for this analysis was presence/absence of fluorosis while the dependent variables were age, gender, gingivitis, periodontitis, caries experience and cost of treatment. The oral hygiene practices and snacking were confounding factors. Agreement rates were determined between assessors, using a Cohen kappa score (agreement rate) was calculated for each assessment (tooth and 
surface) for all children assessed. A median agreement rate was then computed from all individual scores were derived. Analysis of the collected data was achieved through the SPSS version 17.0). The statistical tests which were used were Pearson Chi-square student t-test at a $95 \%$ confidence interval.

\section{Results}

This study involved 248 adolescents aged between 13-17 years with a mean age of 14.75 years $( \pm 1.45 \mathrm{SD}$ ) who were all matched for age and gender. It was noted that the enrolment for boys aged 13-15 years in the schools for North Kajiado was lower compared to the girls with a male to female ratio of $2: 3$ which was not statistically insignificant Pearson Chi-square $=7.6792$; d.f, $p=0.104$ at 95\%CL Figure 1 . The proportion of individuals with dental fluorosis and those without was 1:1. There were 241(97\%) participants born and raised in Kajiado North while $7(3 \%)$ moved to the district before seven years of age. The water for cooking was mainly from the borehole for children with dental fluorosis. The children who used water from the different sources was the same, and most of the study participants consumed borehole water. Most of the tap water was also from boreholes. For the children with fluorosis and those without fluorosis. Dams and river sources were for a minority group as shown in Figure 2.
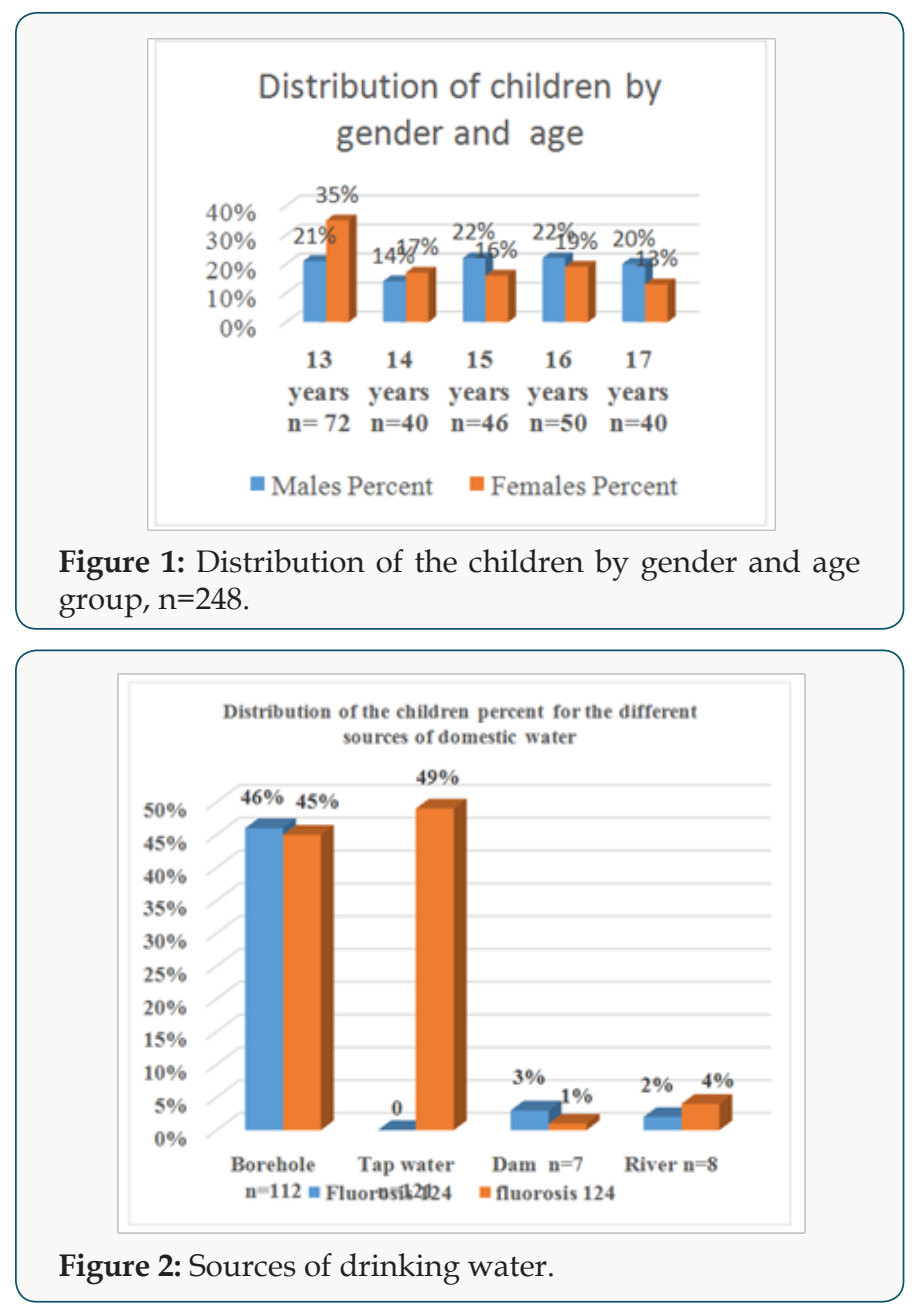

The water fluoride content ranged from between 0,01 to $15 \mathrm{ppm}$. The borehole at Gishagi was at a raised ground recorded low fluoride levels of 0.1 ppm, as well as Kerarapon, springs 0.44 and Lemelepo borehole 0.5 , Ngong main borehole had the recommended levels by WHO of 1ppm. Embulbul roadside and Embulbul community water supplies had very high levels of fluoride at 8.3 and $15 \mathrm{ppm}$ Table 1. The prevalence of dental fluorosis in 3472 teeth of 124 children who were matched for age and gender with 124 without dental fluorosis was $2722(78.4 \%)$ teeth with varying degrees of dental fluorosis. The prevalence of dental fluorosis in the maxillary teeth, TFI score zero for normal teeth was $43(2.5 \%)$ on the buccal-labial/ buccal and palatal. Out of 1733 maxillary teeth, 1685 (97.2) had different scores of severities of dental fluorosis based on the TFI score 1-9 on the buccal/labial/palatal surfaces while 948 (27.3\%) had severities 1-9. TF score 1-3 prevalence was $23.3 \%$ and it affected 809 teeth; TF scores 4-5 affected 2301 (66.2\%) while TF score 6-9 had a prevalence of 1,208 (34.7\%) teeth. The prevalence also varied by the surface, buccal/ facial, or palatal Table 2 .

Table 1: Water fluoride content from sources near the home environs of the children.

\begin{tabular}{|c|c|c|}
\hline Name of water source & Depth in meters & Fluoride level(Mg/l) \\
\hline $\begin{array}{c}\text { Gishagi community water } \\
\text { project }\end{array}$ & 200 & 0.1 \\
\hline $\begin{array}{c}\text { Embulbul roadside water } \\
\text { supply }\end{array}$ & 140 & 15.0 \\
\hline $\begin{array}{c}\text { Embulbul community } \\
\text { water supply }\end{array}$ & 220 & 0.44 \\
\hline Kerarapon springs & unknown & 1.0 \\
\hline Ngong main borehole & 190 & 2.0 \\
\hline Scheme 305 & 180 & 2.5 \\
\hline $\begin{array}{c}\text { Perisho oloika water } \\
\text { project }\end{array}$ & 196 & 2.66 \\
\hline Oloosurutia borehole & 225 & 2.0 \\
\hline Kiserian borehole & 150 & 0.5 \\
\hline Lemelepo borehole & Depth unknown & 1.6 \\
\hline Magadi road borehole & 80 & (190 \\
\hline
\end{tabular}

Table 2: Varying fluorosis degrees on maxillary teeth 1733.

\begin{tabular}{|c|c|c|c|c|c|c|}
\hline \multirow{2}{*}{$\begin{array}{c}\text { TFI } \\
\text { scores }\end{array}$} & \multicolumn{2}{|c|}{$\begin{array}{c}\text { Affected Surfaces } \\
\text { Buccal/facial }\end{array}$} & \multicolumn{2}{c|}{$\begin{array}{c}\text { Affected } \\
\text { Surfaces } \\
\text { Occlusal }\end{array}$} & \multicolumn{2}{|c|}{$\begin{array}{c}\text { Affected Surfaces } \\
\text { Lingual }\end{array}$} \\
\cline { 2 - 7 } & $\begin{array}{c}\mathbf{n =} \\
\mathbf{1 6 8 5}\end{array}$ & Percent & $\begin{array}{c}\mathbf{n} \\
\mathbf{9 9 4 8}\end{array}$ & Percent & $\begin{array}{c}\mathbf{n =} \\
\mathbf{1 6 8 5}\end{array}$ & Percent \\
\hline 0-normal & 48 & 2.8 & 785 & 45.3 & 48 & 2.8 \\
\hline $1-3$ & 310 & 17.9 & 131 & 13.8 & 368 & 21.8 \\
\hline $4-5$ & 876 & 50.5 & 535 & 30.9 & 890 & 52.8 \\
\hline $6-9$ & 499 & 28.8 & 282 & 29.7 & 427 & 25.4 \\
\hline
\end{tabular}

TF scores 1-3 affected 876 (50.5\%) buccal/ labial/ teeth surfaces while TF scores 4-5 were involved 499 (28.8\%). The occlusal surfaces were affected by varying TF score 4-5 affected $535(56.4 \%)$ teeth surfaces and TF scores 6-9 involved 282 (29.7\%) 
occlusal surfaces. Similarly, the palatal surfaces were affected by TF scores 1-3was 368(21.8\%), while TF score 4-5 affected 427 (25.4\%) maxillary teeth surfaces, and TF scores 6-9 affected 890 (52.8\%) surfaces, Table 2.

In the lower jaw out of 1733teeth dental fluorosis affected 1690 teeth giving a prevalence of 97.5 for $\mathrm{TF}$ scores 1-9 and just like in the maxilla, the TFI scores 4-5 were the most frequently recorded out of 3472 teeth for the 124 individuals who had fluorosis. The affected buccal/labial surfaces were 808 (23.3\%) occlusal surface $587(16.8 \%)$ and lingual $845(24.3 \%$, Table 3 . The differences in the distribution of the TF scores in the maxillary and mandibular teeth surfaces was significant was statistically significant difference Chisquare test $=85.67$ d.f $=12, p=0.001$ at $95 \%$ CL. A total of $116(94 \%)$ children with fluorosis and $120(97 \%)$ without fluorosis consumed sugary snacks. A small number of $8(6 \%)$ with fluorosis and $4(3 \%)$ without fluorosis did not consume sugary products, e.g. sweets, cakes /candies, Figure 3.

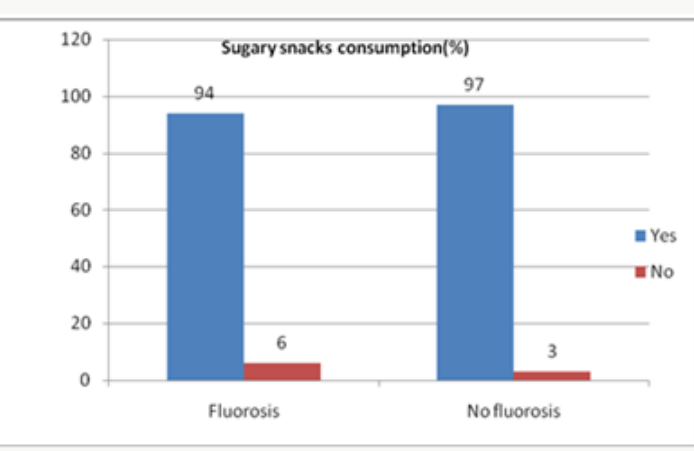

Figure 3: Sugary snacks consumption.

Table 3: Varying degrees of fluorosis on mandibular teeth 1733.

\begin{tabular}{|c|c|c|c|c|c|c|}
\hline $\begin{array}{c}\text { TFI } \\
\text { scores }\end{array}$ & \multicolumn{2}{|c|}{$\begin{array}{c}\text { Affected } \\
\text { Surfaces } \\
\text { Buccal/facial }\end{array}$} & \multicolumn{2}{|c|}{$\begin{array}{c}\text { Affected Surfaces } \\
\text { Occlusal }\end{array}$} & \multicolumn{2}{|c|}{$\begin{array}{c}\text { Affected Surfaces } \\
\text { Lingual }\end{array}$} \\
\hline & $\begin{array}{c}\mathbf{n =} \\
\mathbf{6 9 0}\end{array}$ & Percent & $\mathbf{n = 9 4 5}$ & & $\mathbf{n = 6 9 0}$ & Percent \\
\hline 0-normal & 43 & 1.2 & 1039 & 0 -normal & 43 & 1.2 \\
\hline $1-3$ & 468 & 13.5 & 164 & $1-3$ & 468 & 13.5 \\
\hline $4-5$ & 808 & 23.3 & 587 & $4-5$ & 808 & 23.3 \\
\hline $6-9$ & 414 & 24.5 & 194 & $6-9$ & 414 & 24.5 \\
\hline
\end{tabular}

The frequency consumption of sugary snacks was low for both daily and weekly frequencies in both groups Table 4 . There was no statistical significance for both daily and weekly frequencies with Pearson Chi test square Pearson Chi test $=1.6393$ d.f, $p=0.651$; and a Pearson chi test $=5.2550$ d.f $=3, p=0.154$ at $95 \%$ CL and for children from the two groups. It was noted that $122(98 \%)$ children from each group brushed their teeth. The frequency of brushing was similar for children with dental fluorosis 113(93\%) when compared with those without dental fluorosis 105(88\%). Majority brushed once a day either in the morning after breakfast $61(50 \%)$ and $59(48 \%)$ or in the evening after meals $49(40 \%)$ and $51(42 \%$ for the children with fluorosis and those without fluorosis respectively. Only a small percentage brushed their teeth twice a day. There was an insignificant difference in the timing of brushing between the groups with a Pearson chi test $=4.8939$ d.f $3, p=0.180$ ( $p \leq 0.05$ ). Booth groups the implement for brushing the teeth was a toothbrush while used a chewing Table 3 . The type of tooth brushing aid used was not statistically significant with a Pearson Chi test $=2.4173$, d.f1 $\mathrm{p}=0.120$ at 95\%CL, Table 5 .

Table 4: The frequency of sugary snack consumption.

\begin{tabular}{|c|c|c|c|}
\hline Frequency & & $\begin{array}{c}\text { Fluorosis } \\
\mathbf{( \% 0 0 2 9}\end{array}$ & $\begin{array}{c}\text { No fluorosis } \\
\text { (\%) }\end{array}$ \\
\hline \multirow{4}{*}{ Daily } & Once & $21(18)$ & $14(12)$ \\
\cline { 2 - 4 } & Twice & $24(21)$ & $24(20)$ \\
\cline { 2 - 4 } & Thrice & $15(13)$ & $17(14)$ \\
\cline { 2 - 4 } & Four & $23(20)$ & $24(20)$ \\
\hline \multirow{4}{*}{ Weekly } & Once & $2(2)$ & $8(7)$ \\
\cline { 2 - 4 } & Twice & $10(9)$ & $12(10)$ \\
\cline { 2 - 4 } & Thrice & $13(11)$ & $7(6)$ \\
\cline { 2 - 4 } & Four & $9(8)$ & $15(13)$ \\
\hline
\end{tabular}

Table 5: Brushing aids and timing.

\begin{tabular}{|c|c|c|c|}
\hline $\begin{array}{c}\text { Brushing aid/ } \\
\text { timing }\end{array}$ & Fluorosis (\%) & $\begin{array}{c}\text { No fluorosis } \\
\text { (\%) }\end{array}$ \\
\hline Brushing aid & Toothbrush & $113(93)$ & $105(88)$ \\
\hline & Chewing stick & $8(7)$ & $15(12)$ \\
\hline $\begin{array}{c}\text { Time of } \\
\text { brushing }\end{array}$ & After breakfast & $61(50)$ & $59(48)$ \\
\hline & At night only & $49(40)$ & $51(42)$ \\
\hline & $\begin{array}{c}\text { Morning and at } \\
\text { night }\end{array}$ & $12(9)$ & $12(10)$ \\
\hline
\end{tabular}

The children with fluorosis had lower plaque scores 0.98(0.61) than those without dental fluorosis $1.24(0.69)$ with a statistical significance Pearson Chi-square 3.12 d.f 246; p=0.002 at 95\% CL. The males had a higher plaque score of $1.36(0.67)$ compared to $0.95(0.60)$ for females which were again statistically significant with a Pearson Chi-square $=4.982$ d.f $=246, p=0.001$ at $95 \%$ CL. The gingival Index between the two groups for fluorosis was $0.46 \pm 0.55$, and without fluorosis, the gingival index was $0.48 \pm 0.53$. However the difference was insignificant Pearson Chi-square $=0.196$ d.f 246, $p=0.844$ at $95 \%$ CL. The males had a higher gingival index $0.63 \pm 0.0 .64$ than females who had a mean gingival index of $0.37 \pm 0.43$, and the difference was statistically significant Pearson Chi-square 4.9345 d.f $=1, \mathrm{p} \leq 0.001$ at $95 \%$ CL. The prevalence of gingivitis in both groups was that the mild gingivitis was seen in the majority, 109(88\%) with fluorosis and 107(86\%) without fluorosis. Severe gingivitis had few cases of $2(2 \%)$ and $3(3 \%)$ for the children with fluorosis and without fluorosis respectively.

There was no statistical significance on gingivitis by the group between those who had dental fluorosis and those who did not have dental fluorosis. By gender 139(93\%) of the girls and $77(79 \%)$, boys had mild gingivitis, and the differences in the prevalence of 
gingivitis were statistical significance with a Pearson Chi-square 3.889, d.f $=246, p=0.005$ at 95\%CL. Children who brushed once after breakfast in both groups had plaque scores which were statistically significant one-way ANOVA F $=-2.97, \mathrm{p}=0.003$ at $95 \% \mathrm{CL}$ and the children with fluorosis had the lowest plaque scores of $0.85 \pm 0.5$. The other brushing timings were not statistically significant where Anova was $\mathrm{F}=-1,65, \mathrm{p}=1.02$ (at 95\% CL for at night and $\mathrm{F}=0.44$, $\mathrm{p}=0.664$ at $95 \%$ CL for brushing twice a day. Children with dental fluorosis and who brushed twice daily had higher GI $0.79 \pm 0.8$ compared to those who brushed once [after breakfast $0.35(0.4)$ and at night $0.53(0.6)]$. Children without fluorosis had a GI of 0.47 on average despite the timing of brushing [27-30].

Brushing did not have any influence on the gingival index in both groups either after breakfast, at night only and ofor twice a day, Table 6. Children who suffered periodontitis were only $3(1.2 \%)$ and were from the fluorosis group. None in the group without fluorosis had periodontitis. The overall mean DMFT was low at 0.45(1.15) while it was higher for children with fluorosis 0.54(1.24) and lower $0.36(1.04)$ for children without fluorosis. The statistical difference finding was not a significant difference in the DMFT with a t-test $\mathrm{p}$-value of $0.226(\mathrm{p} \leq 0.05)$ among the two groups. The 14-yearolds with fluorosis had the highest DMFT of 0.91(1.8) compared to that of $0.28(0.56)$ in those without fluorosis in the same age group while the 17- year-olds without fluorosis had the highest DMFT of $0.83(2.1)$.The 13-year-olds with fluorosis had the least DMFT of $0.23(0.69)$ while the 16-year-olds without fluorosis had the least DMFT of 0.08(0.28), Table 7. The DMFT for males compared closely at 0.39 (1.13) for fluorosis and 0.35 (1.22) for the children without fluorosis. The females with fluorosis had a higher DMFT of 0.64 (1.31) compared to those without fluorosis whose DMFT was $0.37(0.93)$. However, the differences were statistically insignificant for boys and the girls with t-test $=-1.10$ d.f $=122, p=0.272$ at $95 \%$ CL for fluorosis and t-test=-1.10 d.f=122, $p=0.891$ at 95\% CL for children without fluorosis. For the children with fluorosis, those who brushed twice did not experience dental caries while the ones who brushed once a day (after breakfast or at night) had a DMFT of $0.5 \pm 1.0$ and $0.73 \pm 1.6$.

Table 6: Brushing habit compared to Gingival Indices.

\begin{tabular}{|c|cc|cc|c|}
\hline $\begin{array}{c}\text { Brushing } \\
\text { frequency }\end{array}$ & \multicolumn{2}{|c|}{$\begin{array}{c}\text { Fluorosis } \\
\text { Gingival Index } \\
\text { (SD) }\end{array}$} & $\begin{array}{c}\text { No fluorosis } \\
\text { Gingival Index } \\
\text { (SD) }\end{array}$ & $\begin{array}{c}\text { Level of } \\
\text { significance } \\
\text { Anova 95\% }\end{array}$ \\
\hline After breakfast & 0.35 & $(0.4)$ & 0.45 & $(0.6)$ & $\begin{array}{c}\mathrm{F}=-1.21 \\
\mathrm{p}=0.228\end{array}$ \\
\hline At night only & 0.53 & $(0.6)$ & 0.49 & $(0.5)$ & $\mathrm{F}=0.36, \mathrm{p}=0.718$ \\
\hline Morning\& night & 0.79 & $(0.8)$ & 0.47 & $(0.5)$ & $\begin{array}{c}\mathrm{F}=1.17, \mathrm{p}= \\
0.252\end{array}$ \\
\hline
\end{tabular}

Table 7: Caries experience by age.

\begin{tabular}{|c|c|c|c|}
\hline $\begin{array}{c}\text { Age in } \\
\text { years }\end{array}$ & $\begin{array}{c}\text { Fluorosis } \\
\text { (SD) }\end{array}$ & $\begin{array}{c}\text { No } \\
\text { fluorosis(SD) }\end{array}$ & $\begin{array}{c}\text { Test of significance } \\
\mathbf{9 5 \% C L}\end{array}$ \\
\hline 13 & $0.23(0.69)$ & $0.38(0.96)$ & 0.79 d.f $4, \mathrm{p}=0.430$ \\
\hline
\end{tabular}

\begin{tabular}{|c|c|c|c|}
\hline 14 & $0.91(1.8)$ & $0.28(0.56)$ & -1.43 d.f $4, \mathrm{p}=0.161$ \\
\hline 15 & $0.5(1.3)$ & $0.33(0.76)$ & -0.53 d.f $4, \mathrm{p}=0.602$ \\
\hline 16 & $0.6(1.2)$ & $0.08(0.28)$ & -2.19 d.f $4, \mathrm{p}=0.033$ \\
\hline 17 & $0.65(1.3)$ & $0.83(2.1)$ & 0.33 d.f $4, \mathrm{p}=0.741$ \\
\hline
\end{tabular}

For the group without fluorosis, there was some caries experience despite the timings for brushing. The difference was statistically insignificant for the time of and duration of brushing, Table 8. Caries experience in association with consumption of sugary snacks for children with fluorosis, the children who consumed sugary snacks twice had a higher DMFT of $0.71 \pm 1.4$ while children without dental fluorosis and consumed four times scored highest DMFT of $0.83 \pm 0.9$. On the weekly snack consumption, individuals who had snacked once had no caries in both groups. The highest DMFT was recorded in those who sacked twice/four times for the fluorosis group who had a mean DMFT of $0.64 \pm 0.6$ while in the group without fluorosis the scores ranged between $0.17-0.25$ despite different weekly snacking times Table 9.

Table 8: Caries experience in association with brushing habit.

\begin{tabular}{|c|c|c|c|}
\hline $\begin{array}{c}\text { Brushing } \\
\text { frequency }\end{array}$ & $\begin{array}{c}\text { Fluorosis } \\
\text { DMFT (SD) }\end{array}$ & $\begin{array}{c}\text { No fluorosis } \\
\text { DMFT (SD) }\end{array}$ & $\begin{array}{c}\text { Pearson chi } \\
\mathbf{9 5 \%} \text { CL }\end{array}$ \\
\hline After breakfast & $0.5(1.0)$ & $0.46(1.3)$ & $\begin{array}{c}0.189 \text { d.f } 2, \\
\mathrm{p}=0.850\end{array}$ \\
\hline At night only & $0.73(1.6)$ & $0.27(0.8)$ & $\begin{array}{c}1.81 \text { d.f } 2, \\
\mathrm{p}=0.073\end{array}$ \\
\hline $\begin{array}{c}\text { Morning and at } \\
\text { night }\end{array}$ & 0 & $0.33(0.9)$ & $\begin{array}{c}-1.27 \text { d.f } 2, \\
\mathrm{p}=0.217\end{array}$ \\
\hline
\end{tabular}

Table 9: Caries experience and frequency of consumption of sugary snack.

\begin{tabular}{|c|c|c|c|}
\hline $\begin{array}{l}\text { Snacking } \\
\text { frequency }\end{array}$ & $\begin{array}{c}\text { Fluorosis } \\
\text { DMFT (SD) }\end{array}$ & $\begin{array}{l}\text { No fluorosis } \\
\text { DMFT (SD) }\end{array}$ & $\begin{array}{c}\text { Anova at } 95 \% \\
\text { CL }\end{array}$ \\
\hline \multicolumn{4}{|l|}{ Daily frequency } \\
\hline Once & $0.62(1.2)$ & $0.21(0.58)$ & $\begin{array}{c}-1.17 \text { d.f } 3 \\
p=0.251\end{array}$ \\
\hline Twice & $0.71(1.4)$ & $0.29(0.89)$ & $\begin{array}{c}-1.24 \text { d.f } 3 \\
p=0.220\end{array}$ \\
\hline Thrice & $0.67(1.4)$ & $0.39(0.85)$ & $\begin{array}{c}-0.70 \text { d.f } 3 \\
p=0.487\end{array}$ \\
\hline Four & $0.48(1.4)$ & $0.83(0.9)$ & $\begin{array}{l}0.72 \text { d.f } 3 \\
p=0.476\end{array}$ \\
\hline \multicolumn{4}{|c|}{ Weekly frequency } \\
\hline Once & None & None & None \\
\hline Twice & $0.64(1.4)$ & $0.17(0.4)$ & $\begin{array}{c}-1.09 \text { d.f } 3 \\
p=0.286\end{array}$ \\
\hline Thrice & $0.38(0.7)$ & $0.25(0.46)$ & $\begin{array}{c}-0.45 \text { d.f } 3 \\
p=0.667\end{array}$ \\
\hline Four & $0.6(1.3)$ & $0.2(0.6)$ & $\begin{array}{c}-1.03 \text { d.f } 3 \\
p=0.314\end{array}$ \\
\hline
\end{tabular}

Despite the similar prevalence of gingivitis among children in both groups, there was an overall increase in disease burden in periodontitis, caries, and fluorosis for children affected by dental 
fluorosis. The difference in the disease burden for those with dental fluorosis and those without was statistically insignificant student t-test paired $t$-test, where $t=1.291$, d.f $=3, p=0.287$ at $95 \% \mathrm{CL}$. The dietary snacking habits indicated that 116(94\%) children with fluorosis and 120(97\%) without fluorosis consumed sugary snacks. A small number of $8(6 \%)$ with fluorosis and $4(3 \%)$ without fluorosis did not consume sugary products, e.g., sweets, cakes / candies Figure 4.

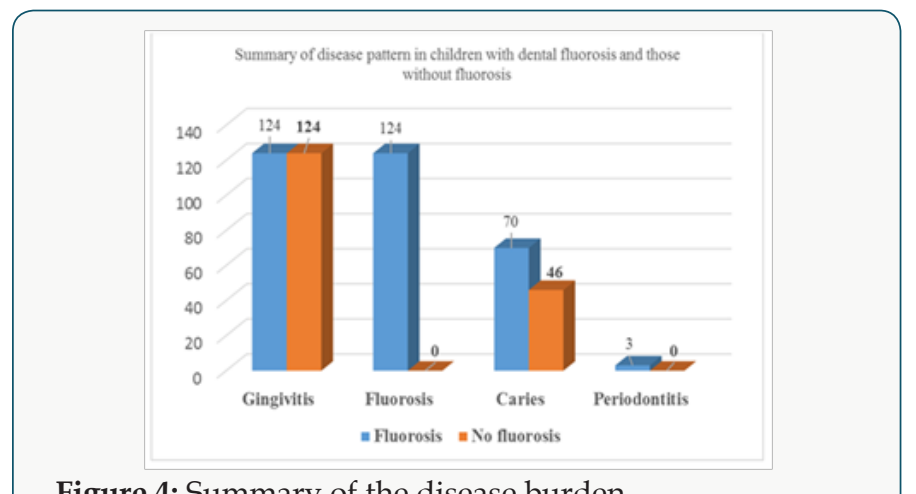

Figure 4: Summary of the disease burden.

\section{Discussion}

This finding was contrary to the Kenyan Population and Housing Census which documented that there were more males than females among children aged 13-17 years [30,31]. The salient differences in gender low school enrolment for the boys may be influenced by the culture of moranism as most boys would prefer to engage in cultural activities rather than be in school. However, for the last thirty-four years the government policy has been to emphasise the girl child, and therefore the boy child may have been left abandoned to face the challenges to the changing demands of life to himself there is a need to investigate this disparity in gender attention. The study was carried out in Kajiado North has high fluoride. The healthy teeth had the TF score zero, and the enamel had a translucency after prolonged air drying) were considered as not having dental fluorosis. Moreover, this was similar to a study by Makhanu et al. [14]. The drinking water supply was mostly from boreholes for children affected and those not affected by fluorosis although there was spring that supplies a small number from the communal boreholes which could further increase the number of children of children exposed to high fluoride. Water from dams and rivers was used by few children. The current study found fluoride content in Gishagi and Lemelepo to be below the recommended levels by WHO of $1 \mathrm{mg} /$ litre. Other boreholes found in the same locality had fluoride levels ten times higher. These two boreholes were at different altitudes, and seasonal variation may have played a role in the differences. The depth of the boreholes may also be a factor in fluoride concentration64. The children without dental fluorosis might have consumed water from the boreholes which had low fluoride levels. The communal borehole at Gishagi fluoride level was lower compared to that of spring water. Children from Gishagi and Lemelepo were found to have dental fluorosis despite the low fluoride levels in water meaning they may have been taking high fluoride water while at school or a high fluoride diet. The spring water in Kajiado was found to have $0.44 \mathrm{mg} / \mathrm{l}$ of fluoride which was within the levels reported by Opinya (1992) in Kenya [32]. Similar levels of fluoride were reported in Kajiado District by Nair, et al. [33]. In the present study, there were seven boreholes with fluoride levels between $1-15 \mathrm{mg} / \mathrm{l}$ which were above the recommended standards $[34,35]$. The current study also found two boreholes namely Embulbul roadside water supply and Embulbul community water supply with the highest levels 8.3 and $15 \mathrm{mg} / \mathrm{l}$; these could have contributed to the severe degrees of fluorosis found in the children.

In this study, the overall disease burden for the children with dental fluorosis was high compared to those without and was statistically significant (Chi test $p=<0.001$ ). All the children suffered from some form of gingivitis; the finding correlates well with other studies by Hugoson in Sweden and Ng'ang'a [36,37] in Kenya. The differences in the gingival index were statistically insignificant. The gingival index when compared to the timing of brushing, the scores did not differ significantly. Children with fluorosis did not exhibit severe inflammation expected from plaque retention on the rough surfaces of the teeth and so further studies to find out the reason are recommended although it could be that the oral hygiene habits of these children were good. The research established that most children had moderate fluorosis TFI 4-5 whose level of pitting was not severe hence reduced inflammation. These findings differ from those by Waweru in Kenya who found those with fluorosis had a higher prevalence of gingivitis and that the prevalence of people with fluorosis was over $30 \%$ whereas, in places where borehole water is used, $100 \%$ fluorosis manifests [38,39].

The males had a higher GI than females attributed to the poor oral hygiene practices in boys when compared to girls, and the difference was statistically significant $p=<0.001(p \leq 0.05)$. It was also found that brushing did not have any influence on the GI scores for both groups although the children who brushed twice a day had highest plaque scores and so maybe their brushing technique was faulty. The timing of brushing was not statistically significant $\mathrm{p}=0.180(\mathrm{p} \leq 0.05)$ as well as tooth brushing aid $p=0.120(p \leq 0.05)$. This study found those with fluorosis had a lower PS of 0.98 compared to mean plaque score of 1.24 for those without fluorosis irrespective of the time of brushing which was statistically significant $p=0.002(p \leq 0.05)$. The differences in the plaque score could be explained by the fact that fluoride inhibits plaque retention on the tooth surfaces as shown by Anuradha, et al. [40]. Males had a higher mean plaque score of $1.36(0.67)$ compared to females, and the differences in the man plaque scores were statistically significant $p=<0.001(p \leq 0.05)$. The difference may imply that the girls with low plaque scores had good oral hygiene practices as found out in Iran by Neamatollahi, et al. [41] the overall prevalence of periodontitis was $1.2 \%$, and this was only noted in children suffering from dental fluorosis. There was a low prevalence of periodontitis in this study when compared to what 
was reported in the USA by Brown, et al. [42] of 15\%.There was an association of periodontitis with dental fluorosis, and the results were similar to those of a study by Vandana et al. [43]. However, Haikel in Morocco and Anuradha in India found that the prevalence of periodontitis decreased with increased concentration of fluoride in drinking water [44-46].

The overall prevalence of dental caries was relatively high at $116(46.8 \%)$. Children with fluorosis had a higher prevalence of $70(56.5 \%)$ probably due to a high predisposition to caries resulting from the pitting caused by dental fluorosis, while it was lower for those without fluorosis 46(36.3\%). The difference between the DMFT was statistically insignificant. Decayed, filled and missing teeth in the current study were low $0.45 \pm 0.15$. However, but similar to that found by Ng'ang'a [6] The low DMFT values reported could have arisen from the design of the current study which was comparative or the absence of radiographs to diagnose interproximal caries. The finding that most teeth surfaces exhibited moderate fluorosis TFI 4-5 could have played a protective role similar to the results by Aldosari in Saudi Arabia and Iida in the USA $[16,46]$. There was a direct relationship between severity of dental fluorosis and dental caries in this study, and the same was found in South Africa by Ockerse and Makhanu et al. in Kenya [4,13]. However, in Namibia Berndt reported that high concentrations of fluoride in drinking water alone did not result in dental caries since it is a multifactorial disease [17].

The DMFT for males in the two groups was similar and was not statistically significant $\mathrm{p}=0.272(\mathrm{p} \leq 0.05)$. The females with fluorosis had higher DMFT of 0.64(1.31) compared to that of those without fluorosis $0.37(0.93)$ which was not statistically significant $\mathrm{p}=0.891(\mathrm{p} \leq 0.05)$. In this study, the frequency of brushing had an inverse relationship with caries experience for the children with fluorosis while it did not influence those without fluorosis where the DMFT was lower irrespective of the brushing habits. Sugary snack consumption had a direct relationship with caries experience on both daily and weekly intake, and the effect was more in the children with fluorosis.

The 14-year-olds with fluorosis were found to have had the highest DMFT of 0.91(1.8) compared to $0.28(0.56)$ in those without fluorosis of the same age group, and it was difficult to explain this finding. It is likely that children aged 14 years with fluorosis consumed sugary snacks more than the rest in the group or they had poor oral hygiene, or their teeth had been predisposed to caries by the dental fluorosis. The 17-year-old children without fluorosis had the highest DMFT of $0.83(2.1)$. The high DMFT may be attributed to the number of years the teeth had been in the oral cavity hence predisposed to plaque and bacteria demineralization in the presence of increased snack intake. The children aged 13 years with fluorosis had the least DMFT of $0.23(0.69)$ while those aged 16 years without fluorosis had the least DMFT of 0.08(0.28). In the maxillary and mandibular teeth, the TFI scores of 4-5 were the most common accounting to about half the teeth surfaces examined, unlike TFI 6-9 which was expected to be higher due to the high levels of Fluoride in borehole water. The teeth in the premolar and molar regions are exposed to masticatory forces which lead to attrition. Enamel that is fluorosed is week an unable to withstand the masticatory forces. The wear and tear of the surface, therefore, may appear normal resulting in false positives of what seems to be healthy enamel $[47,48]$.

Hence, the TFI scores recorded may have been lower than the initial severity. Alternatively, families may have used a different water source from the present or the use of mixed water sources. Also, there have been reported to be dietary influences by Opinya or seasonal variations by Ockerse in the fluoride content in underground water $[8,32]$. Similar comparative studies done on dental fluorosis in the same age group were not found, although in Tanzania Roman 10 found $65.4 \%$ to have had TFI 6-9, while $29.4 \%$ had TFI [4-5].

\section{Conclusion}

Children with dental fluorosis were burdened more by dental diseases, the treatment needs were higher among those affected by dental fluorosis for caries experience, periodontitis, and fluorosis and those with dental fluorosis had periodontitis compared to those who did not have dental fluorosis. The basic fee guidelines were forty-five times what is recommended at the sub-county level.

\section{References}

1. Kaimenyi JT (2004) Oral health in Kenya. International Dental Journal 54: $378-382$.

2. Rosenberg JD (2010) MedlinePlus Encyclopedia Dental Cavities. Advanced Dental Care, Palm Beach Gardens, FL Review provided by Veri Med Healthcare Network.

3. WHO (2003) The World Oral Health Report. Continuous improvement of oral health in the $21^{\text {st }}$ centur p.12.

4. Nganga PM, Valderhaug J (1992) Dental caries in primary school children in Nairobi, Kenya, Acta Odontologica Scandinavica 50(5): 269-272.

5. (2015) Ministry of health Kenya National Oral Health Survey Report

6. Nganga PM (2002) Afr J Oral Hlth scie 3: 103-110.

7. Owino RO, Masiga MA, Nganga PM, Macigo FG (2010) Dental caries, gingivitis and the treatment needs among 12-year-olds. East Afr Med J 87(1): 25-31.

8. Ockerse T (1941) Endemic fluorosis in the Kenhardt and Gordonia districts, South Africa. Journal of the American Dental Association 28(6): 936-941.

9. Rodrigues CRMD, Ramires Romito ACD, Zardetto CGDC (2002) Abordagem educative preventiva em odontopediatria. In: Cardoso RJA, Gonçalves EAN. Odontopediatria. São Paulo: Arte Ciência pp.113-136.

10. Chibole 0 (1988) Dental caries among children of high fluoride regions of Kenya. JR Sock Health 108(1): 32-33.

11. Cunha Cruz J, Nadanovsky P (2005) Dental fluorosis increase caries risk. J Avid Based Dent Pract 5(3): 170-171.

12. Tagliaferro EP, Ambrosano GM, Meneghim Mde C, Pereira AC (2008) Risk indicators and risk predictors of dental caries in schoolchildren. J Appl Oral Sci 16: 408-413. 
13. Thylstrup A, Fejerskov O (1978) Clinical appearance of dental fluorosis in permanent teeth in relation to histological changes. Community Dent. Oral Epidemiol 6(6): 315-328.

14. Makhanu M, Opinya G, Mutave RJ (2009) Dental fluorosis caries experience and snack intake of 13-15-year-olds in Kenya. East Afr Med J 86(3): 120-124.

15. Wondwossen F, Astrøm AN, Bjorvatn K, Bårdsen A (2004) The relationship between dental caries and dental fluorosis in areas with moderate and high fluoride drinking water in Ethiopia. Community Dent Oral Epidemiol 32(5): 337-344.

16. Iida H, Kumar JV (2009) The association between enamel fluorosis and dental caries in US schoolchildren. J Am Dent Assoc 140(7): 855-862.

17. Berndt Ch, Meller Ch, Poppe D, Splieth ChH (2010) Fluorosis caries and oral hygiene in schoolchildren on the Ombili Foundation in Namibia. Oral Health Prev Dent 8(3): 269-275.

18. Rodrigues CRMD, Ramires-Romito ACD, Zardetto CGDC (2002) Abordagem educative-preventiva em odontopediatria. In: Cardoso RJA Gonçalves EAN. Odontopediatria. São Paulo: Arte Ciência pp 113-136.

19. (1934) Dean HT: Classification of mottled enamel diagnosis. J Am Dent Assoc 21:1421-1426.

20. Dean HT (1942) The investigation of physiological effects by the epidemiological method. In: Moulton FR, editor. Fluorine and dental health. Pub. No. 19. Washington (DC): American Association for the Advancement of Science 23-31.

21. Horowitz HS, Driscoll WS, Meyers RJ, Heifetz SB, Kingman A (1984) A new method for assessing the prevalence of dental fluorosis the Tooth Surface Index of Fluorosis. J Am Dent Assoc 109(1): 37-41.

22. Pendrys DG (1990) The Fluorosis Risk Index: a method for investigating risk factors. J Public Health Dent 50: 291-298.

23. Rozier RG (1994) Epidemiologic indices for measuring the clinical manifestations of dental fluorosis: overview and critique. Adv Dent Res 8(1): 39-55.

24. Roman F, Mabelya L, Sarita P (2010) Dental fluorosis: impact and treatment need in Tanzania. The Preliminary Program for IADR East \& Southern African Division Annual Meeting and Scientific Conference.

25. Marshall TA, Levy SM, Warren JJ, Broffitt B, Eichenberger Gilmore JM, et al. (2004) Associations between Intakes of Fluoride from Beverages during Infancy and Dental Fluorosis of Primary Teeth. J Am Coll Nutr 23(2): 108-116.

26. Beltrán Aguilar ED, Barker L, Dye BA (2010) Prevalence and Severity of Dental Fluorosis in the United States, 1999-2004. NCHS Data Brief 53 1-8.

27. World Health Organization: Oral health surveys: basic methods $-5^{\text {th }}$ edn.

28. Loe H, Silness J (1963) Periodontal disease in pregnancy I. Prevalence and severity. Acta Odontol Scand 21: 533-51.

29. Löe H (1967) The Gingival Index, the Plaque Index and the Retention Index Systems. J Periodontol 38(6): 610-616.

30. Fluorides, Hydrogen Fluoride, and Fluorine 250. 7 Analytical Methods Colorimetry; EMSLC Method 340.1 EPA 1998c

31. (2009) The Kenya National Bureau of Statistics (KNBS) Kenya Population and Housing analytical Reports
32. Opinya G N (1992) Daily fluoride intake and toxicity in rural Kenyan children and 13-17 year olds (Age 0 -17). University of Nairobi, Jomo Kenyatta Memorial Library AFR RK 341.062.

33. Yee R, Sheiham A (2002) The burden of restorative dental treatment for children in Third World countries. Int Dent J 52(1): 1-9.

34. Ramraj C, Azarpazhooh A, Dempster L, Ravaghi V, Quiñonez C (2012) Dental treatment needs in the Canadian population: analysis of a nationwide cross-sectional survey. BMC Oral Health 12(46): 1-9.

35. Nair KR, Manji F, Gitonga JN (1984) Challenges in African Hydrology and Water Resources: The occurrence and distribution of fluoride in ground waters of Kenya. (Proceedings of the Harare Symposium, July) 1 AHS Publ No 144.

36. Hugoson A, Koch G, Rylander H (1981) Prevalence and distribution of gingivitis-periodontitis in children and 13-17-year-olds. Epidemiological data as a base for risk group selection. Swed Dent J 5: 91-103.

37. Waweru L (2006) Dental caries, fluorosis and periodontal disease among 12-15-year-old children from Juja in rural Kenya. A Thesis submitted in partial fulfillment of a Master's Degree in Paediatric Dentistry, School of Dental Sciences, and the University of Nairobi, Kenya.

38. Dean HT, McKay FS (1939) Production of mottled enamel halted by a change in common water supply. Am J Public Health 29(6): 590-596.

39. Ainamo J, Barmes D, Beagrie G, Cutress T, Martin J, et al. (1982) Development of the World Health Organization (WHO) Community Periodontal Index of Treatment Needs (CPITN). Int Dent J 32(3): 281291.

40. Anuradha KP, Chandrashekar J, Ramesh N (2002) Prevalence of periodontal disease in endemically flourosed areas of Davangere Taluk, India. Indian J Dent Res 13(1): 15-19.

41. Sherwood IA (2010) Fluorosis varied treatment options. J Conserv Dent 13(1): 47-53

42. Brown LJ, Brunelle JA, Kingman A (1996) Periodontal status in the United States, 1988-1991: Prevalence, extent, and demographic variation. J Dent Res 75: 672-683.

43. Vandana KL, Reddy MS (2007) Assessment of periodontal status in dental fluorosis subjects using community periodontal index of treatment needs. Indian J Dent Res 18(2): 67-71.

44. Haikel Y, Turlot JC, Cahen PM, Frank R (1989) Periodontal treatment needs in populations of high- and low-fluoride areas of Morocco. J Clin Periodontol 16(9): 596-600.

45. Ainamo J, Barmes D, Beagrie G, Cutress T, Martin J, et al. (1982) Development of the World Health Organization (WHO) Community Periodontal Index of Treatment Needs (CPITN). Int Dent J 32(3): 281291.

46. Aldosari AM, Akpata ES, Khan N (2010) Association among dental caries experience, fluorosis and fluoride exposure from drinking water sources in Saudi Arabia. Journal of Public Health Dentistry 70(3): 220-226.

47. Fomon SJ, Ekstrand J, Ziegler EE (2000) Fluoride intake and prevalence of dental fluorosis: trends in fluoride intake with particular attention to infants. Journal of Public Health Dentistry 60(3): 131-139.

48. Marshall TA, Levy SM, Warren JJ, Broffitt B, Eichenberger Gilmore JM, et al. ( 2004) Associations between Intakes of Fluoride from Beverages during Infancy and Dental Fluorosis of Primary Teeth. Journal of American College of Nutrition 23(2): 108-116.

Citation: Gladys N O, Mavindu M N. Dental Disease Burden Snacking, and Tooth Brushing Habits and Among 13-17-Year-Olds with Fluorosis Compared to those without Dental Fluorosis in Kajiado Kenya. Mod App Dent Oral Health 2(2)- 2018. MADOHC.MS.ID.000134. DOI: 10.32474/ MADOHC.2018.02.000134. 
(C) This work is licensed under Creative

To Submit Your Article Click Here: $\quad$ Submit Article

DOI: 10.32474/MADOHC.2018.02.000134

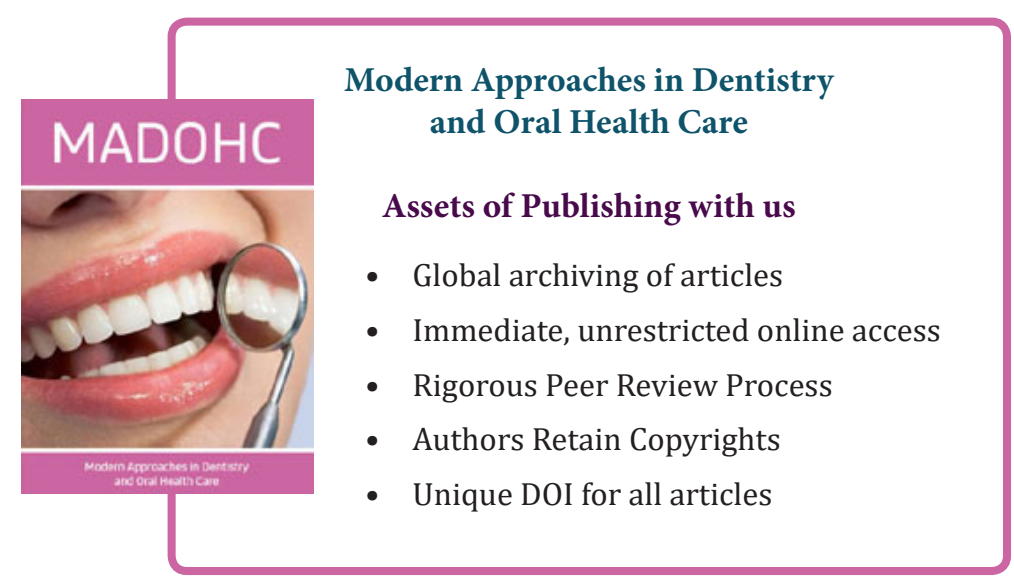

